\title{
Educação ainda que tardia: a exclusão da escola e a reinserção de adultos das camadas populares em um programa de EJA*
}

\author{
Geovânia Lúcia dos Santos
}

Universidade Estadual de Minas Gerais, Faculdade de Educação

\section{Introdução}

Libertas qua será tamem: na tradução do latim para o português tem-se a expressão que revela a aspiração de um povo que, vivendo sob o jugo da dominação colonial, ansiava pela "Liberdade ainda que tardia". Grafado na bandeira do Estado de Minas Gerais, o dístico revela a permanência da "bandeira" da liberdade que, passados mais de duzentos anos, ainda não se fez completa.

Quando eu percebi essa coisa do estudar, do voltar, do poder, então, assim, eu me percebo podendo modificar isso tudo. E uma das coisas que realmente mais modificou na

* Artigo elaborado com base na dissertação de mestrado realizada sob a orientação do professor Leôncio José Gomes Soares e defendida no Programa de Pós-Graduação em Educação da Faculdade de Educação da Universidade Federal de Minas Gerais, em julho de 2001. Apresentado no GT Educação de Pessoas Jovens e Adultas, durante a $25^{\mathrm{a}}$ Reunião Anual da ANPEd, realizada em Caxambu, MG, de 29 de setembro a 2 de outubro de 2002. minha vida foi isso comigo mesma, o meu Eu liberto. É isso o que eu estou sentindo hoje. A minha vida profissional e financeira não mudou em nada, mas eu sou livre. Isso é ser feliz. É você poder olhar de frente para o outro e falar: Oi, como é que vai? Isso é ser feliz! Então eu acho que valeu a pena, vale a pena estudar. Claro que não vou poder tudo com lápis e papel na mão, claro que não, mas bastante coisa eu posso, com certeza! Até o direito de ser livre eu tenho, eu posso! Não é adquirir coisas, é você poder se sentir, se posicionar diante da vida e diante das pessoas. Isso é que é legal! É de não ter vergonha de olhar a minha cara no espelho; eu não tenho vergonha de mim, eu me sinto bem comigo mesma. Eu não estou ganhando nada com isto, sinceramente, não melhorou nada na minha vida ter estudado assim, financeiramente não. Não mudei de casa, não comprei carro... Mas quem sabe um dia, não é não? Vou continuar, eu estou tentando, é por aí. (Trecho da entrevista com Maria)

"Educação ainda que tardia". Para além da construção bem-sucedida de uma paráfrase, a escolha dessa expressão por jovens e adultos de um programa de Educação de Jovens e Adultos (EJA), como lema grafado em camisetas, revela a permanência da luta 
por liberdade, pelo fim ou, no mínimo, pela amenização de uma situação de opressão que data dos primórdios da era colonial. Tendo perpassado os 500 anos de nossa história, essa situação se faz perceber, nos nossos dias, de uma maneira que, segundo alguns estudiosos, nunca fora tão acentuada.

Diante da descoberta da utilização dessa expressão, uma questão que já havia se colocado de forma ainda embrionária ganhou mais força: será que a conquista do direito à educação pelos alunos em questão representa - tal como a luta dos inconfidentes, na qual os sujeitos se inspiraram para verbalizar essa conquista - uma face da luta que empreendem, cotidianamente, em favor da realização da cidadania, mesmo que parcial e tardia? O que levou esses alunos a estabelecerem um paralelo tão explícito entre a conquista do direito à educação, ainda que tardiamente, e o dístico da bandeira do Estado? Foi em busca de resposta a essa e a muitas outras perguntas dela derivadas que se desenvolveu uma pesquisa da qual alguns resultados serão apresentados neste texto.

Que impactos a vivência da negação do direito à educação elementar completa, via exclusão precoce da escola, e a vivência de uma experiência de escolarização tardia geram na vida de adultos das camadas populares? Nessa pergunta incluem-se todas as inquietações surgidas a partir da prática docente junto a jovens e adultos que, tendo sido excluídos precocemente da escola, buscaram, através de uma oportunidade educacional no campo da EJA, a melhoria de sua formação escolar.

Pelo que se pode observar através de seu enunciado, a pergunta se estende a dois extremos: por um lado, a exclusão precoce da escola que vitima, ano após ano, enormes contingentes da população brasileira aos quais se nega, através desse mecanismo, o direito à educação básica completa. No outro extremo, a reinserção de uma pequena parcela desses enormes contingentes na escola, na busca da continuidade da formação escolar outrora interrompida.

Largamente estudado nos meios acadêmicos, o primeiro extremo - exclusão precoce da escola - já deu fortes indicações de ser um dos maiores proble- mas do sistema educacional brasileiro, cujo protelamento da solução compromete a construção de uma sociedade mais justa e igualitária. Em contrapartida, tendo recebido uma atenção um pouco menor nos círculos acadêmicos, pode-se afirmar, entretanto, que o segundo extremo - reinserção na escola - vem emergindo paulatinamente nos estudos, o que propicia um maior entendimento do campo da EJA e de questões diversas a ele correlatas. ${ }^{1}$

Embora ambos os extremos figurem em pesquisas (cada qual com uma determinada proporção e enfoque), pelo que se pôde apreender da análise da produção teórica, há uma relativa ausência de elementos que auxiliem na compreensão da maneira como sujeitos que foram excluídos precocemente da escola vivenciam essa experiência, bem como os impactos que a mesma gera em suas vidas futuras. Ao se considerar a questão da reinserção na escola, identifica-se uma realidade semelhante: ausência relativa de elementos que possibilitem o entendimento de como se dá a vivência dessa experiência e dos impactos que a mesma gera em suas vidas futuras.

O trabalho investigativo realizado consistiu em uma tentativa de resgatar esse sujeito para compreender, a partir de sua fala, como esses fenômenos do sistema educacional brasileiro são vivenciados e o que deles resulta para aqueles que os experienciam, inscrevendo-se nos campos temáticos da EJA: Exclusão Social/Exclusão da Escola e Educação e Cidadania. Esses campos temáticos foram articulados entre si e, posteriormente, essa articulação foi confrontada com dados empíricos coletados especificamente para esse fim.

${ }^{1}$ No caso específico da reinserção, trabalhos investigativos recentes têm enfocado jovens e/ou adultos em processo de escolarização tardia. Assim, muito embora não tenham como foco o fenômeno da reinserção na escola por parte dos que dela foram excluídos precocemente, considera-se que essas pesquisas o contemplem, ainda que indiretamente, uma vez que são referidas a sujeitos que o vivenciam, no momento mesmo de tal vivência. Como exemplo, têm-se trabalhos como os de Almeida (2002), Araújo (2001), Fonseca (2001), Jorge (1999), Parenti (1999). 
Constituindo-se em uma pesquisa do tipo qualitativa, a análise referenciou-se nos estudos de François Dubet e Silvia Duschatzky, pautando-se pela compreensão da experiência escolar e dos resultados do fazer educativo com base nos sujeitos para e sobre os quais esse fazer se desenvolve. Tal referência mostrou-se pertinente uma vez que, analisando a possibilidade de compreender a ação educativa, Dubet e Martuccelli afirmam que:

Para comprender lo que fabrica la escuela, no basta estudiar los programas, los roles y los métodos de trabajo, es necesario también captar la manera con que los alumnos construyen su experiencia, "fabrican" relaciones, estrategias, significaciones através de las cuales se constituyen en ellos mismos. Hay que ponerse en el punto de vista de las funciones de sistema. La experiencia social no es objeto positivo que se observa y mide fuera como una práctica, como un sistema de actitudes y de opiniones, porque es un trabajo del actor que define una situación, elabora jerarquías de sección, construye imágenes de sí mismo. (1996, p. 15)

Essa perspectiva de análise é corroborada por Duschatzky, que, ao pesquisar acerca da experiência escolar de jovens de setores populares da Argentina que vivem em contextos de pobreza, com o objetivo de compreender os vínculos que eles estabelecem com a instituição escolar, também optou por privilegiar as narrativas dos mesmos acerca da experiência vivenciada no interior da instituição:

Las escuelas a la que aludimos son las escuelas vividas, subjetivizadas, no por personas consideradas individualmente, sino por grupos sociales inscriptos en particulares condiciones de existencia. Entonces, más que indagar los modos en que la escuela realiza su papel integrador o diferenciador, más que detectar las maneras en que las tecnologías de poder operan en los discursos educativos, pretendemos capturar los "usos" simbólicos que se producen no interior de un sistema controlado y prescriptivo. Nuestra mirada pone entre paréntesis la función de la escuela para detenerse en la experiencia educativa. (1999, p. 21)
Portanto, no trabalho de análise dos dados coletados durante a pesquisa buscou-se analisar a vivência da exclusão precoce da escola e da experiência de escolarização tardia, bem como os impactos advindos dessas experiências vivenciadas por adultos das camadas populares, com base nas narrativas construídas pelos próprios sujeitos. ${ }^{2}$

Com relação à exclusão precoce da escola, interessava compreender tanto a maneira como ela ocorreu, quais seus motivadores, quanto suas implicações na vida dos sujeitos. Assim, as narrativas não se detiveram na exclusão em si; elas se ampliaram, incorporando outras esferas da vida dos egressos, evidenciando a forma como essa ocorrência específica acabou impactando e determinando, de certa maneira, outros acontecimentos.

No caso da reinserção na escola, o objetivo foi um pouco além. Mais que compreender seus motivadores, a maneira como fora vivenciada e seus impactos na vida dos sujeitos, interessava apreender em que medida a relação que se estabelece no plano teórico entre educação e cidadania se confirma quando à negação do direito à educação elementar completa segue-se a conclusão desse ciclo de escolarização através da inserção em um programa de EJA. Assim, além da tentativa de apreender os impactos da reinserção na escola na vida desses sujeitos, buscou-se, paralelamente, levantar elementos que pudessem indicar se, de fato, a educação (que nesse caso é considerada como a conquista de um direito anteriormente negado) pode contribuir para a efetivação da cidadania.

Para a realização dos objetivos inicialmente propostos fez-se a opção de pesquisar alunos egressos do Projeto de Ensino Fundamental de Jovens e Adul-

${ }^{2}$ Essas narrativas foram construídas com base na realização de entrevistas, voltadas para a reconstituição temática da história de vida. Pelas narrativas, as trajetórias de escolarização foram reconstituídas, abarcando desde o primeiro ingresso na escola, ainda na infância, até a conclusão das experiências de escolarização tardia vivenciadas já na fase adulta. 
tos do Centro Pedagógico da Universidade Federal de Minas Gerais, $2^{\circ}$ Segmento, PROEF II, que consiste em uma oportunidade educacional voltada para $\mathrm{o}$ atendimento a jovens e adultos pouco escolarizados. Esse projeto foi criado em 1986 em resposta à demanda formulada por alguns professores do Centro Pedagógico e por um grupo de funcionários da universidade, através de seu órgão representativo ASSUFEMG $^{3}$.

Funcionando desde sua criação nas instalações da escola de ensino fundamental da universidade, no horário noturno e com o auxílio financeiro da PróReitoria de Extensão da UFMG, o curso tem como objetivo geral o desenvolvimento de uma prática pedagógica voltada para a educação de jovens e adultos, e como objetivos específicos:

[...] atender aos servidores da Universidade [o que foi estendido a jovens e adultos da comunidade em geral] com o primeiro grau incompleto, proporcionando-lhes uma experiência de escolarização equivalente a este nível de ensino; possibilitar a licenciandos uma formação inicial de educadores de jovens e adultos e possibilitar a docentes e licenciandos a realização de pesquisas no campo da educação de jovens e adultos. (Programa de Educação Básica de Jovens e Adultos, 1998, p. 19)

Assentando-se, portanto, sobre o trinômio da "prestação de serviço à comunidade (extensão), a formação de profissionais (ensino) e a produção de conhecimento (pesquisa)", que representa "as três dimensões do trabalho universitário" (idem, p. 18), o PROEF II vem, desde a sua criação, desenvolvendo

${ }^{3}$ Atualmente, o PROEF II se liga ao Núcleo de Educação de Jovens e Adultos da Faculdade de Educação da mesma universidade, oferecendo a funcionários da instituição e à comunidade em geral um curso de suplência referente às quatro últimas séries do ensino fundamental ( $5^{\mathrm{a}}$ à $8^{\mathrm{a}}$ série). O núcleo abriga ainda o PROEF I e o PEMJA (Programa de Ensino Médio de Jovens e Adultos), nos quais se desenvolvem, respectivamente, o primeiro segmento do ensino fundamental e o ensino médio. atividades formativas e firmando-se, cada vez mais, como um "espaço de pesquisa e formação de educadores e de realização de uma proposta de Educação de Jovens e Adultos que pode prestar uma contribuição significativa para a vida dos educandos e para a produção e divulgação de conhecimento na área" (idem, p. 40).

Baseado em uma proposta pedagógica que se pretende adequada às necessidades formativas e às especificidades do educando jovem e adulto, o curso caracteriza-se, entre outras coisas, pelo compromisso de oferecer aos educandos um ensino regular de suplência no qual se "procura formar o cidadão que a 'terceira revolução industrial' demanda, isto é, aquele indivíduo autônomo, que sabe pensar, criativo, e não um repetidor de tarefas" (idem, p. 8).

A escolha de quatro egressos de tal instituição como sujeitos da pesquisa justifica-se pelo fato de a mesma se apresentar como uma proposta que busca oferecer ao educando jovem e adulto uma oportunidade educacional voltada para o atendimento de suas necessidades formativas básicas, pretendendo, assim, realizar o objetivo de desenvolver um ensino de qualidade, conforme consta em seu programa. Portanto, além de perceber a maneira como os adultos que foram excluídos precocemente da escola e a ela retornaram tardiamente vivenciaram tais experiências e quais os impactos das mesmas em suas vidas, objetivou-se, igualmente, perceber em que medida os ideais formativos propalados pela instituição se realizam e são apreendidos pelos que concluíram ali a educação elementar.

\section{Alguns resultados da pesquisa}

Conforme foi exposto anteriormente, no início da pesquisa, perguntava-se quais seriam os impactos que a vivência da exclusão precoce da escola e de uma experiência de escolarização tardia geram na vida de adultos das camadas populares. Essa pergunta se desdobrava em uma segunda, na qual explicitava-se o interesse de compreender em que medida a análise da exclusão e posterior reinserção na escola permiti- 
ria verificar se existe, de fato, uma relação entre educação e formação para a cidadania, conforme tese defendida por alguns expoentes do pensamento educacional.

Embora no momento de sua formulação essa pergunta tenha se desdobrado em duas, e essas tenham adquirido uma certa autonomia entre si, na realização da pesquisa bem como na sistematização de seus resultados evidenciou-se que a resposta a ambas as perguntas provinha de uma mesma origem. Isso porque a análise das narrativas demonstrou que um dos impactos mais evidentes da vivência da experiência de escolarização tardia pelos sujeitos pesquisados consiste no fato de eles terem vivenciado, na EJA, "um conjunto de situações educativas" (Dayrell, 1989, p. 331), que lhes permitiu acessar um amplo leque de conhecimentos e informações. Com base nisso lhes foi possível, se não criar, no mínimo ampliar a identificação de si mesmos como cidadãos e a compreensão de seu papel enquanto sujeitos, tanto de direitos quanto de deveres.

Os exemplos colhidos das narrativas que deram margem para que tal constatação se fizesse não foram poucos: em diversos momentos os sujeitos pesquisados evidenciaram que a vivência da experiência de educação tardia lhes possibilitou bem mais do que eles esperavam. Isso porque, para a maioria, a escola ganhava significado sobretudo por sua função cartorial. ${ }^{4}$ Dentre esses exemplos, destaca-se o trecho apresentado na introdução deste artigo, no qual se verifica que, para além da melhoria na condição socioeconômica - aspirada, porém, não atingida -, a

${ }^{4} \mathrm{~A}$ análise dos registros feitos na época do ingresso dos sujeitos no PROEF II e as conversas com eles sobre sua inserção no mesmo deixam claro que a busca pela ampliação da formação escolar deveu-se predominantemente à crença de que o certificado de conclusão de um nível da escolarização lhes possibilitaria melhorar as condições de ingresso e/ou permanência no mercado de trabalho. A escola, portanto, era vista como a instituição que, tal como um "cartório", lhes conferiria um documento comprobatório, uma credencial que os habilitaria melhor para a vida pública. escolarização tardia possibilitou a Maria acessar um leque de conhecimentos que passaram a fundamentar sua autopercepção, bem como o entendimento de que: "claro que não vou poder tudo com lápis e papel na mão, mas bastante coisa eu posso [...]”. Estudar, nesse contexto, deixa de ser unicamente o meio através do qual torna-se possível "adquirir coisas, é você poder se sentir, se posicionar diante da vida e das pessoas". 5

Esse processo de ressignificação da escola, cujo resultado mais significativo identificado com a pesquisa relaciona-se diretamente à possibilidade de a educação contribuir na luta em favor da efetivação dos direitos da cidadania, também foi manifestado explicitamente por José, que fez a seguinte afirmação:

\section{[...] ter concluído o supletivo no CP foi uma das melhores passagens da minha vida! No início pensei no lado finan- ceiro que traria no futuro, mas no decorrer do curso, à me- dida que o conhecimento vinha chegando o lado financeiro ficou para trás. Tornar-me um cidadão foi e será o mais importante, pois deixei de ser manipulado e entender todo o sistema que no Brasil e no mundo existem. Passei a co- nhecer melhor o meu corpo, situar-me no meu País e no continente. Entender o que acontece nas escolas públicas no nível de primeiro grau e segundo, enfim, toda explora- ção que existe sobre aqueles que não têm o mínimo de co- nhecimento. (José)}

Diante dessa constatação, poderíamos considerar que a pergunta referente aos impactos da vivência dessa experiência na vida dos sujeitos está parcialmente respondida, estando a pergunta referente à relação entre educação e cidadania respondida de for-

${ }^{5}$ No tratamento das entrevistas, optou-se por organizar as narrativas na forma de um texto no qual falas literais dos entrevistados são intercaladas com interferências da pesquisadora. Tais interferências se fizeram de modo a dotar as narrativas de uma seqüência temporal e lógica nem sempre presente no momento da entrevista. Os destaques em itálico constituem expressões literais retiradas das entrevistas. 
ma integral. Entretanto, a riqueza das narrativas, dos dados coletados e das análises desenvolvidas evidenciou, de certa maneira, a estreiteza dos objetivos iniciais da pesquisa, impondo, por conseguinte, a necessidade de ir além da satisfação de tais objetivos a fim de se tentar contemplar ao menos parte dessa riqueza.

Segue, portanto, a apresentação de algumas outras constatações derivadas do desenvolvimento da pesquisa.

\section{A exclusão em si: análise das causas para além do que foi manifestado nas narrativas}

A análise das falas referentes à interrupção dos estudos revelou que esse acontecimento é vivenciado de maneiras diferentes pelos sujeitos que o experienciam. Entretanto, se há diferenças no modo como o fato de ser excluído da escola é entendido e vivido por cada um, ao analisar horizontalmente as trajetórias percebeu-se haver, no interior dessa aparente diversidade, maneiras bastante próximas de vivenciá-lo. ${ }^{6}$

Destaca-se, nesse sentido, o entendimento que os sujeitos têm a respeito da interrupção dos estudos. Há, na produção teórica do campo educacional, uma concepção acerca do fracasso escolar nos meios populares que identifica a interrupção dos estudos antes da conclusão da educação elementar como resultante de um silencioso processo de exclusão que o sistema educacional põe em funcionamento desde o ingresso desses alunos na escola. Contudo, as falas dos sujeitos da pesquisa que foram vitimados nesse processo demonstram que essa compreensão ainda está muito

${ }^{6}$ A opção por desenvolver uma análise vertical das entrevistas em particular, e uma horizontal, relacionando-as entre si, se fez seguindo a indicação de Michelat, segundo a qual "a atenção particular dedicada à singularidade de cada entrevista é concomitante a um relacionamento das diversas entrevistas entre si. Isso conduz a alternar leituras verticais das entrevistas (guardando a lógica própria de cada uma) e as leituras horizontais, para estabelecer a relação com as outras entrevistas" (1980, p. 206). limitada ao plano acadêmico, não fazendo parte do universo argumentativo deles. Assim, o que na literatura educacional e no entendimento desta pesquisa é considerado como um fenômeno provocado pelo próprio sistema educacional e pela estrutura social da qual ele deriva aparece, nas justificativas dos sujeitos por ele atingido, como sendo o resultado de suas opções, de suas limitações pessoais e/ou das limitações de suas famílias. ${ }^{7}$

Isso fica evidente quando se considera, por exemplo, a narrativa de João acerca de sua escolarização inicial, ${ }^{8}$ que se deu de forma fragmentada: primeiramente em uma escola rural, depois em um curso que era uma espécie de MOBRAL, criado à noite para adultos, mas que acabou não dando certo, e depois em um supletivo. João fala que a segunda tentativa não deu certo por causa do cansaço e do desinteresse, e que durante o pouco tempo em que funcionou estruturavase da seguinte maneira: "Tinha dia que a professora não ia, outro dia o lampião não acendia, outro dia estava chovendo, enfim, a coisa foi realmente minando. [...] você ia lá, pegava o material e voltava".

Refletindo ainda em torno dessa questão, ele se remete às condições de trabalho na fazenda em que vivia, que muitas vezes demandava a interrupção dos estudos: "Às vezes as crianças faltavam porque elas faziam falta para os pais; não se mantinha o filho na

${ }^{7}$ É importante ressaltar que mesmo os sujeitos que demonstraram, ao longo da entrevista, uma compreensão mais ampla da relação entre sua situação pessoal/familiar e a estrutura socioeconômica circundante, mantiveram uma atitude de autoculpabilização em relação à interrupção dos estudos na escolarização inicial. É possível que esse fato se deva ao nível de interiorização, por parte dos mesmos, da responsabilidade pela interrupção dos estudos. Entretanto, a permanência desse entendimento constitui uma ambigüidade cuja compreensão ainda está para ser construída.

${ }^{8}$ Considerou-se "escolarização inicial" como sendo o período decorrido entre o primeiro ingresso na escola e a exclusão da instituição e/ou o período decorrido entre esse ingresso e a conclusão do curso primário, hoje correspondente ao primeiro segmento do ensino fundamental. 
aula porque estava precisando, ele fazia falta, arar a terra, na época da colheita...".

O lento processo de exclusão vivenciado por José, que culminou com sua saída da escola, foi descrito por ele da seguinte maneira:

\section{[...] eu lembro muito bem, eu era menino, que as condições eram mínimas, a gente tinha que escrever... Era tipo assim, você pegava um pedaço de papel de pão que fosse e você escrevia no papel de pão porque não tinha condições, não tinha a mínima condição não. Para chegar no colégio eu lembro que eu morava no Ipiranga e estudava no Juscelino Kubitschek, eu andava uma média de uns 4 a $5 \mathrm{~km}$ para poder ir para a escola. E tudo era difícil demais... E aquele troço todo e muita dificuldade... E aí o que é que aconte- ceu? À medida que a gente foi crescendo, o trabalho se tornou muito mais importante que o estudo. (José)}

Assim, ele e parte dos irmãos tiveram que parar de estudar para manter a família, para ajudar: "Porque... ajudava um pouquinho daqui, um pouquinho dali...". Apesar de todas as dificuldades, ele insistiu na tentativa de concluir sua formação escolar básica, conciliando trabalho diurno e estudo noturno. As dificuldades assumiram nova forma, fazendo-se sentir de modo ainda mais intenso:

No início eu tentei, eu tentei. Foi quando eu fiz a $5^{\mathrm{a}}$ série, eu fiz a Admissão ao Ginásio, fiz o $1^{\circ}$ ano do Ginasial à noite, eu estudava à noite! Então, eu falo a partir da minha própria experiência, porque eu saía do serviço, trabalhava geralmente no serviço pesado, pegava uma jornada violenta no serviço, e o que acontecia: ia para o colégio à noite e aquilo ficava muito difícil, entendeu? Tudo começou sabe como, porque eu não conseguia acompanhar o desenvolvimento do restante da turma, não conseguia. E aí o que acontecia: começava a chegar as notas vermelhas, eu ficava invocado pra caramba... O estudo não estava tendo o retorno. Geralmente o professor chegava, explicava um troço no quadro e aquilo... Sei lá, parece que não entrava, entendeu? E aquilo foi me cansando, cansando... [...] aí fica difícil, fica difícil pelo seguinte, porque eu senti na pele que estava ficando pesado para mim. (José)
Para Solange, a interrupção dos estudos representou o fim de uma situação de constrangimentos vivenciada durante toda a escolarização inicial:

Meu pai raspava e aplicava sinteco, só que o que ganhava era para beber. Minha mãe lutou muito, com muita dificuldade. Aí que parei de estudar, por causa de problema familiar mesmo, com meus doze anos. Pelo fato de ter assim, de não ter caderno, livro direito, ter que ficar pegando emprestado e tudo, com esses problemas da família que veio mesmo a parar de estudar. (Solange)

Conforme pode-se perceber pelos relatos apresentados acima, a exposição das causas que levaram à interrupção dos estudos foi feita na forma da apresentação de alguns fatores - em sua maioria ligados a questões financeiras, à dificuldade de conciliar trabalho e estudo, ou, ainda, à própria incapacidade de acompanhar os estudos e/ou ao desânimo que essa atividade provocava. Da análise de tais argumentos percebeu-se que as causas apresentadas para a interrupção dos estudos apontavam para a existência de uma tendência à simplificação do processo por parte dos que o vivenciaram, uma vez que fatores isolados foram tomados como explicação da não-continuidade da formação escolar.

Entretanto, a percepção de que tanto o ingresso quanto a permanência na escola no período da escolarização inicial se deram sob o signo da dificuldade constituiu um indicativo irrefutável de que a exclusão da escola resultou do agravamento, bem como do somatório das dificuldades identificadas nesses dois momentos que a antecedem. Isso significa que, diferentemente de constituir-se em um fato isolado, provocado por uma razão específica, a exclusão deve ser entendida como um processo complexo de exclusão na escola.

Diante disso, outro destaque que chamou a atenção quanto à maneira como os sujeitos vivenciaram a exclusão da escola foi o fato de as falas referentes à primeira interrupção dos estudos apontarem invariavelmente para uma autoculpabilização, ou, quando muito, para a culpabilização dos pais, mas nunca para 
a identificação das causas dessa interrupção no interior da própria escola e/ou no sistema educacional e social. $^{9}$

À autoculpabilização e/ou culpabilização da família seguiu-se uma tendência à naturalização da exclusão, por parte daqueles que a experienciaram: as narrativas acerca da exclusão precoce da escola evidenciaram que, para os sujeitos da pesquisa, a interrupção dos estudos constituiu, tal como o ingresso na escola, um caminho natural. Isso porque não se percebeu nos relatos a existência de elementos que apontassem para algum tipo de estranhamento em relação à situação. No geral, é como se eles estivessem percorrendo um caminho já conhecido, fazendo exatamente aquilo que deles se esperava.

Essa aparente naturalização da interrupção dos estudos entre estudantes das camadas populares é confirmada por Dayrell (1989), quando afirma que, com a exclusão da escola realiza-se "a determinação de um quantum educacional deste grupo social. Através de mecanismos sutis, a 'exclusão escolar' aparece como um caminho natural e, para muitos, desejado, liberando estes jovens para assumirem integralmente sua condição de trabalhadores" (1989, p. 85).

É provável que a aceitação, por parte dos sujeitos entrevistados, da interrupção dos estudos como algo natural, constitutivo mesmo de suas trajetórias, deva-se ao fato de eles não perceberem as possíveis consequiências que esse acontecimento poderia vir a gerar em suas vidas no futuro. A impossibilidade de visualizar, logo no início, as dificuldades que seriam enfrentadas mais adiante, em decorrência do fato de serem pouco escolarizados, destaca-se também como um dos fatores comuns aos sujeitos pesquisados, no que se refere à maneira como vivenciaram a exclusão da escola.

${ }^{9}$ A esse respeito, Chaui, afirma que "[...] a ambigüidade fundamental da instrução está em ser portadora de dupla consciência: a do direito e a da espoliação, e como esta possui a leveza do imaginário, a consciência popular procura lidar com a segunda, oferecendo-lhe justificações plausíveis" (1986, p. 171).
Contudo, essa impossibilidade de visualização do futuro deve ser relativizada, uma vez que é bastante difundida, nos meios populares, a idéia de que "aquele que não estuda puxa carroça", vai ser "oreia seca" ou "motorista de fogão". ${ }^{10}$ Ou seja, sabe-se que, quando se sai da escola, as possibilidades em relação ao futuro profissional e à inserção social ficam reduzidas a poucas opções. Entretanto, parece haver uma diferença entre a difusão dessas idéias, sua interiorização e as reações diante da exclusão da escola, já que em alguns casos ela é recebida até com uma certa dose de alívio, pois pode representar a liberação de uma sobrecarga de atividades, ou mesmo de uma atividade desgastante, da qual se auferia poucos resultados, como no caso de José.

Um outro aspecto cuja compreensão tornou-se possível com base na análise da exclusão precoce da escola foram as diferentes maneiras pelas quais se evidenciou a interiorização, pelo sujeito, do fracasso escolar e os efeitos dessa interiorização em sua vida e na relação que ele estabeleceria com a escola no futuro. Dessa maneira, as análises desenvolvidas acerca da exclusão precoce da escola possibilitaram concluir que o impacto mais evidente de sua vivência pelos sujeitos consistiu na construção de uma autopercepção negativa, que, se por um lado os colocava no lugar do não-saber, por outro lado, acabou servindo como um mecanismo propulsor no sentido de mobilizá-los na busca da melhoria da formação escolar.

\footnotetext{
${ }^{10}$ Muito utilizada entre os trabalhadores da construção ci-
} vil, a expressão "oreia seca" designa o servente de pedreiro e possivelmente, sua generalização nos meios populares seja uma forma de referir-se às pessoas portadoras de baixa escolaridade, que não possuem qualificação profissional e que, portanto, ocupam o nível mais baixo da hierarquia profissional. No caso da expressão "motorista de fogão", tem-se a mesma explicação, uma vez que ela é utilizada para designar as empregadas domésticas que, segundo uma concepção predominante, o são por possuírem baixa escolaridade e/ou por não possuírem melhor qualificação profissional. 
A percepção da condição de pouco escolarizado, que se construiu nos diversos constrangimentos sociais que os sujeitos experimentaram no futuro, acabou se revelando um dos principais motivadores da decisão a favor do retorno aos bancos escolares. Assim, no âmbito da pesquisa que se realizou, foi possível perceber que a percepção negativa que tinham de si em relação aos estudos, somada aos constrangimentos sociais decorrentes da baixa escolaridade, exerceu forte influência no processo de transformação da demanda potencial por escolarização em demanda efetiva.

\section{Escolarização tardia}

Da análise das narrativas acerca do processo que tornou possível aos egressos a criação de condições tanto para ingressarem quanto para permanecerem no programa até a conclusão do curso, veio a seguinte constatação: muito embora a existência de oportunidades educacionais acessíveis e adequadas aos demandatários da EJA seja uma condição fundamental para que eles possam retomar e dar seguimento à sua formação escolar, essa condição, por si só, não é suficiente para que eles obtenham êxito. Para além da existência do local onde se possa estudar, é necessário que haja a convergência de um conjunto de elementos que, no contexto da pesquisa, foram considerados como motivadores/facilitadores. Motivadores porque, para assumirem a identidade de estudantes, na fase adulta, esses sujeitos precisaram estar imbuídos de muita motivação. Facilitadores porque, apesar da motivação e da existência da oportunidade educacional, existiram outras barreiras cuja superação só se tornou possível porque lhes foram oferecidas e/ou conquistadas algumas facilidades ao longo do processo. Pelo que foi narrado acerca da experiência de escolarização tardia, percebeu-se que foi graças à existência de fatores dessa natureza que eles puderam superar as dificuldades, os obstáculos e os temores que se fizeram presentes durante todo o período em que estiveram no PROEF II.

A percepção dessa realidade evidenciou que, diferentemente do que se pensava inicialmente, se a inexistência de oportunidades educacionais acessíveis para jovens e adultos pouco escolarizados constitui uma grave negação de seu direito a uma formação escolar básica, regular, pública e de qualidade, a existência pura e simples de uma oportunidade dessa natureza não representa, por si só, uma resposta a esse direito, muito embora represente um passo bastante significativo em sua direção.

Dessa maneira, a realização da pesquisa possibilitou perceber que, de fato, no caso de adultos pouco escolarizados ou não-escolarizados, "não basta oferecer escola; é necessário criar as condições de frequência, utilizando uma política de discriminação positiva, sob risco de, mais uma vez, culpar os próprios alunos pelos seus fracassos" (Haddad, 1998, p. 116).

Dentre as dificuldades enfrentadas, destaca-se o processo seletivo prévio ao ingresso no PROEF II, que foi mencionado pelos entrevistados. ${ }^{11}$ Ao falarem sobre a prova de seleção, a primeira idéia que Solange, Maria e José deixaram transparecer foi a de susto, seguido de uma sensação comum de que não conseguiriam ser aprovados, em virtude do longo período de afastamento dos bancos escolares:

Ai eu liguei pr'aqui e eles me informaram que tinha que vir e fazer a inscrição e se passasse na prova de seleção não teria que pagar nada, que só teria que comprar caderno, que as apostilas eles mesmos davam. E eu vim e fiz a prova e pensei: "Não vou passar não, dez anos sem estudar!". (Solange)

Eu lembro que eu vim, tinha que fazer uma prova de seleção. Eu falei assim: "Acho que eu não vou conseguir fazer aquilo não!’. Aí peguei, no dia lá, animei e vim, acabou que consegui. (José)

${ }^{11} \mathrm{O}$ processo de seleção que se realiza para o ingresso dos alunos no programa possui três etapas: inscrição de candidatos, prova para aferir os candidatos aptos a cursarem o nível correspondente à $5^{\mathrm{a}}$ série do ensino fundamental e sorteio de vagas entre os selecionados na segunda etapa. 
Para além dessa justificativa, o temor provocado pelo saber-se obrigado a se submeter às provas de seleção parece poder ser explicado também pela via da baixo auto-estima. Possuindo uma trajetória de escolarização marcada por fracassos (em alguns casos sucessivos) e uma trajetória de vida na qual a vivência de constrangimentos pela pouca escolaridade foi uma constante, é natural que esses sujeitos ficassem apreensivos e temerosos diante de situações nas quais lhes fosse demandado expor seus conhecimentos, uma vez que se colocavam (e foram socialmente colocados) no lugar do não-saber. ${ }^{12}$

Embora pareça à primeira vista um mal necessário, a prova de seleção à qual tiveram que se submeter surtiu um efeito positivo, passando de elemento dificultador a um forte motivador para a retomada dos estudos. Isso porque o temor inicial foi superado e eles passaram a se ver como portadores de um conhecimento legitimado pela escola. Ou seja, ao se verem como capazes de enfrentar, com sucesso, um exame de seleção, eles tiveram a auto-estima elevada, aumentando, assim, a disposição para os estudos:

E aí quando eu vim para saber o resultado, o meu nome estava lá no quadro. Ô gente, mas aí foi uma alegria,

foi uma satisfação tão grande! (Solange)

No caso de José, a motivação parece ter sido ainda maior, porque ele não apenas foi bem-sucedido nas provas, como o foi a ponto de ser classificado diretamente para a segunda etapa do curso: ${ }^{13}$

${ }^{12}$ Com relação aos impactos que o fracasso escolar gera naqueles que são suas vítimas, Zago afirma que "a interiorização do fracasso, além de outros efeitos relacionados à auto-estima, certamente não favorece uma relação positiva com a escola" (2000, p. 33).

${ }^{13}$ Quando eventualmente o candidato apresenta um domínio acima do mínimo esperado nas habilidades de leitura, interpretação e cálculos matemáticos básicos, a comissão encarregada do processo seletivo pode deliberar pela inserção do mesmo nas etapas posteriores do curso. No caso de José, houve o encaminhamento para a segunda etapa do curso, correspondente à $6^{\mathrm{a}}$ série.
Eu não passei pelo sorteio, não. Tinha o sorteio, mas eu fui assim, sem classificação, entendeu? Eu já entrei... foi assim, ao invés d'eu entrar na $5^{\text {a }}$ série, eu entrei na Turma II. Eu me senti assim, muito orgulhoso. Tipo assim, no meio de duzentos e cinqüenta alunos, eu não ter que entrar no sorteio e ter conseguido já entrar para... classificado direto sem entrar no sorteio... Nem passar! É por aí, eu fiquei, por dentro, eu fiquei todo orgulhoso de ter conseguido! Entendeu? (José)

O fato de o PROEF II se desenvolver no interior da universidade, sendo parte integrante da instituição, destacou-se, nas quatro narrativas, como um grande motivador. Em alguns casos, essa especificidade significou a ampliação do horizonte de possibilidades, ao permitir que os alunos tivessem contato com um grande número de pessoas que gozavam de uma situação diferente da sua e, por isso mesmo, aspirada:

Ah, [estar na universidade] incentiva muito mais você estudar, até mesmo você ver o transitar de alunos... O estar lá dentro, com certeza, te dá mais força, mais disposição de estudar e ver que você pode chegar lá, naquela posição que o aluno, que você está vendo ali, sabe? [...] Dentro do preparatório eu não podia nem me imaginar dentro de uma faculdade, eu nem tinha noção de como era uma faculdade, sinceramente! Lá no CP não, no CP não só tive noção como eu pude ver, pude entrar numa biblioteca, sabe, um monte de coisa... e saber que eu posso, inclusive, usar aquela biblioteca, que qualquer um pode chegar lá e pegar um livro, sabe, e ler... Quer dizer, isso é muito importante, isso ajuda demais! Isso amplia, não só amplia os horizontes da gente como te dá mais vontade de continuar, sabe? Te dá mais garra, é isso! Eram coisas completamente diferentes, é como se fosse um outro mundo, aquela escola! (Maria)

Esse fato também possibilitou, conforme explicitado na fala transcrita acima, que os egressos desmistificassem a instituição. Podendo ter acesso a seus mais diversos espaços e acervos e experimentar parte do que havia ali, eles construíram um modo novo de percebê-la. Ver-se ali também possibilitou que eles se percebessem como sujeitos de direitos e de co- 
nhecimentos, uma vez que na imagem que tinham até então aquele era um espaço de "privilegiado, crânio, cabeção [...], só pessoa superdotada", ${ }^{14}$ de pessoas que possuíam uma trajetória caracterizada pela longevidade escolar, graças a uma situação financeira favorável, ou por serem muito inteligentes, ou pela combinação dos dois fatores. Portanto, ao estarem ali, eles se viam também como "privilegiados", ou como sujeitos que, mesmo não possuindo as características dos estudantes da universidade, adquiriram o direito de vivenciar a experiência de estudar em uma instituição pública de prestígio que, acreditavam, lhes ofertaria uma formação de boa qualidade. ${ }^{15}$

A maneira como foram recebidos no projeto também parece ter sido um grande motivador. Sendo citado com maior ênfase por Maria, o fato de ser vista e, por conseguinte, passar a se ver como sujeito, portador de uma história, de experiências, de aspirações, expectativas e até de temores, ao qual foi dada a oportunidade de se colocar, de se apresentar, diferentemente do que havia acontecido nas outras experiências de retomada dos estudos que vivenciara, aparece como um grande diferencial:

[...] no preparatório, enquanto você tinha um número, era um número lá na sala, no meio daquele bando de gente, o professor sozinho, lá na frente, falando para aquele bando de gente... Aí você chega no CP, eles já... A primeira coisa você sente a diferença: a entrevista, a conversa, o perguntar o que você pretende fazer... Aquilo já te deixa assim: "Ah, cheguei, agora estou em casa! Posso começar, aqui dá!”. Sabe, é isso. Eu acho que isso faz muita diferença,

${ }^{14}$ Essa expressão foi utilizada por José ao se referir aos alunos da universidade.

${ }^{15}$ Nos depoimentos de outros egressos com os quais se fez contato durante a pesquisa, uma das justificativas mais recorrentes para o ingresso no PROEF II é a idéia, por eles alimentada, de que, por se tratar de um curso desenvolvido no interior da universidade, seria melhor que os outros. Essa idéia se expressava pela utilização de termos como "qualidade", "seriedade", "compromisso" e outros correlatos. porque você se sente já valorizado ali, sabe? Você já se sente assim, mais... é, em casa mesmo! Você já se sente mais: “Ôpa, aqui eu posso! Aqui eu já estou podendo!”. Sabe, assim: “Eu existo aqui!". Lá não, lá eu era um número no meio daquela multidão... sem rosto, entendeu? E isso, para quem está voltando a estudar depois de um longo período, faz muita diferença: é você ter o seu rosto, é você ser identificado. E isso é importante. Para mim foi, eu acho! Te dá aquela... Aí você sente assim que você pode, que ali você vai! Porque no outro não tive, tanto é que eu não continuei. Não só por dificuldade financeira, mas porque eu achei, assim, não tinha... (Maria)

Esse sentimento de acolhimento, contrário ao de exclusão antes vivenciado, apontado por Maria como um dos fatores fundamentais que a fez acreditar que ali, no PROEF II, ela permaneceria, parece ter sido compartilhado por uma parcela bastante significativa dos alunos que por ali passaram, sendo invariavelmente apontado por eles como uma das melhores lembranças da experiência de escolarização tardia vivenciada no Projeto. ${ }^{16}$

Muito embora o fato de se constituir como uma boa lembrança seja digno de ressalva, o tratamento dispensado aos alunos ganha relevo porque é possível atribuir a essa prática parte da responsabilidade pelos

${ }^{16}$ Essa recepção, que se iniciava no momento da inscrição para o processo seletivo através da exposição das características do projeto e de uma conversa com os futuros candidatos, é descrita da seguinte maneira no programa do Projeto de Ensino Fundamental: "O semestre deve iniciar-se com um encontro entre estes [os alunos] e os monitores, utilizando também um questionário, com perguntas que ampliam o universo de informações sobre os mesmos. É comum, neste primeiro momento, depararmos com alunos que passaram até vinte anos sem freqüentar uma escola e que chegam com dificuldade de se expressarem verbalmente, de falar em público e de escrever. Esta constatação vem reforçar a importância das atividades de desinibição, de entrosamento da turma, e de dinâmicas que desenvolvem a oralidade do aluno e a conquista de novos espaços culturais e de convivência" (Programa de Educação Básica de Jovens e Adultos, 1996, p. 9). 
resultados que eles apresentaram em seu processo de escolarização, e mesmo por sua permanência ou não. A abertura de um espaço para a fala, para a manifestação desses sujeitos cujas trajetórias de vida e de escolarização são caracterizadas, normalmente, pela ausência desse espaço, aliada ao fato de serem ouvidos e, mais que isso, de perceberem interesse pelo que tinham a dizer sobre si mesmos, parece ter surtido um efeito bastante positivo. Isso os fez perceber que tinham o que dizer e que o conteúdo de suas falas era importante, na medida em que os revelavam para os outros e para si mesmos, sendo incorporado ao processo de ensino-aprendizagem que ali se desenvolvia.

$O$ fato de estarem no interior de uma instituição cuja proposta pedagógica baseava-se na valorização dos conhecimentos prévios dos educandos, na negação da simples transmissão de um conhecimento tido como válido e na aposta em um processo de construção do conhecimento no qual o educando precisava se colocar como sujeito, parece ter representado um choque para eles, que estavam habituados a uma escola cuja pedagogia prima pela transmissão do conhecimento e pela negação de toda e qualquer possibilidade de o aluno emergir como sujeito no processo ensino-aprendizagem. ${ }^{17}$

Analisando a relação que os jovens estabelecem com a escola, quando a ela retornam, no referente à fala, Dayrell percebeu:

Os depoimentos deixam clara a relação existente entre a autoconcepção negativa, a palavra e o poder. Essa

${ }^{17}$ Segundo consta no Programa de Educação Básica de Jovens e Adultos do Centro Pedagógico, "o conhecimento do percurso cognitivo dos aprendizes é outro princípio que se procura adotar. Temos procurado avançar nas leituras, discussões e reflexões sobre a investigação dos conhecimentos prévios que os alunos trazem a partir de suas vivências e experiências (extra-escolares e escolares) e sobre os papéis que tais conhecimentos devem desempenhar nas estratégias de ensino-aprendizagem ali elaboradas e empreendidas, na escolha de conteúdos, nas dinâmicas de sala de aula e nas atividades extraclasse" (1996, p. 5). mesma relação pode ser constatada na dificuldade que apresentam, inicialmente, em participar das aulas perguntando, questionando, em expressar-se de qualquer forma em público. A aparente apatia e passividade, tão reclamadas pelos professores dos cursos noturnos, fazem parte do mesmo conjunto de problemas. Diante de alguém que consideram superior, no trabalho ou na escola, ou num meio que não o deles, calam-se, envergonham-se, sentem-se tímidos. De um lado, a insegurança diante do código lingüístico dominante, imposto como legítimo, que lhes foi negado pela própria escola. Em um e outro, a atribuição individual da culpa: o que é a imposição social do silêncio, torna-se para eles timidez e "falta de cultura". Mas não só. O próprio poder de falar entre iguais é relativo. E o é porque a questão não se resume apenas no falar, mas também na qualidade do que se fala. (1989, p. 325)

Assim, o "resgate do desejo de aprender" constituía a primeira grande tarefa que a instituição deveria realizar com os educandos, com o intuito de criar as condições necessárias para seguir desenvolvendo sua ação educativa. Conforme demonstram Souza et $a l$. , esse resgate "passa necessariamente pelo resgate do sujeito do processo de aprendizagem. Resgates possíveis a partir de uma prática docente que considere o aprender em uma dimensão mais ampla: no âmbito do conhecimento, da valorização da palavra e da autonomia e da inclusão de valores éticos e sociais" $\left(1999\right.$, p. 14). ${ }^{18}$

Da parte do educando, resgatar esse desejo significava assumir-se como sujeito do próprio conhecimento, sujeito de direitos e, mais que isso, do uso da fala. No caso dos egressos sobre os quais recaiu o foco desta pesquisa, esse resgate parece ter deman-

${ }^{18}$ De acordo com o Programa de Educação Básica de Jovens e Adultos, "todo trabalho desenvolvido no Projeto Supletivo procura situar o aluno trabalhador como agente no processo de aprendizagem, um ser concreto, portador de uma bagagem de experiências. É necessário, portanto, criar um espaço democrático na sala de aula para os alunos se expressarem, possibilitando um maior conhecimento de sua realidade" (1996, p. 9). 
dado um esforço ainda maior, pois, conforme já foi discutido, no referente à relação com a escola e com o conhecimento, eles assumiam uma posição de inferioridade. Portanto, colocar-se no lugar de sujeito de conhecimentos, capaz de participar ativamente do processo de ensino-aprendizagem que se desenvolveria a partir e em função do repertório de conhecimentos e vivências que ele acumulou ao longo de sua vida, demandava a construção de uma nova maneira de ver e entender a escola e sua função social; demandava a "revaloración de si mismos y uma reconstrucción de su autoestima" (Llosa et al., 2001, p. 32).

Embora a gratuidade dos estudos no PROEF II representasse um grande facilitador para todos, ela não era suficiente para garantir a permanência no curso. Isso porque havia outros dificultadores de ordem financeira a serem enfrentados. Os alunos sabiam (provavelmente porque o sentiam no bolso) que, do ponto de vista financeiro, a decisão de retomar os estudos implicava custos que poderiam ser bastante elevados. Em sua narrativa, Solange expressou com bastante clareza essa questão, ao afirmar que:

[...] só de saber que eu não ia ter que pagar escola, não é?

Porque com filhos, na época eu estava mexendo lá em casa, pelo menos era uma economia que eu já vinha a fazer! [...] a gente fala que escola aqui é de graça. Não, gente! Sabe quantos ônibus eu gastava pra mim vir aqui dependendo do lugar onde eu estava? Seis ônibus por dia. Com o preço que está a passagem, o que eu ganhava metade era pra passagem, a outra metade deixava em casa pra comprar pão, leite, os meus cigarros. Então, praticamente eu estava trabalhando pra estudar. (Solange)

O fato de não impor aos alunos a obrigatoriedade da aquisição de material didático, garantindo-lhes o fornecimento de materiais produzidos ali, pelas equipes da área, compatíveis com o desenvolvimento da ação educativa desenvolvida, também se destacou na narrativa dos entrevistados e no depoimento de outros egressos como mais um elemento motivador/ facilitador. Através desse recurso os alunos não só se livravam da despesa com material tão comum nas oportunidades educacionais no campo da EJA, como também tinham acesso a um material de qualidade, planejado, elaborado e/ou organizado especificamente para a satisfação de suas necessidades formativas.

Como não era possível se livrar das despesas de transporte, a análise demonstrou que os egressos foram construindo maneiras próprias de lidar com a situação, aproveitando-se dos elementos facilitadores que emergiam nesse campo. No caso de João e José, o problema do transporte não se fez notar, pois estudavam no local de trabalho, ficando livres de possíveis despesas extras. ${ }^{19}$ No caso de Maria, a estratégia adotada implicava um esforço físico, acompanhado por uma perda relativa de tempo:

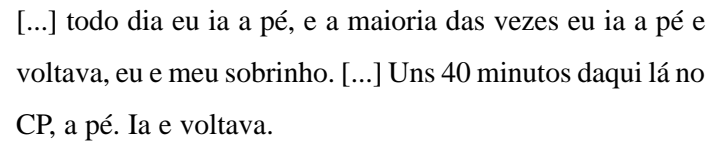

Nessas caminhadas, ela tinha a companhia do sobrinho que a havia convencido a voltar a estudar consigo. E, apesar do desgaste, ela revela que fazer o percurso a pé tinha como compensação o fato de acabar se transformando em um momento de socialização e lazer:

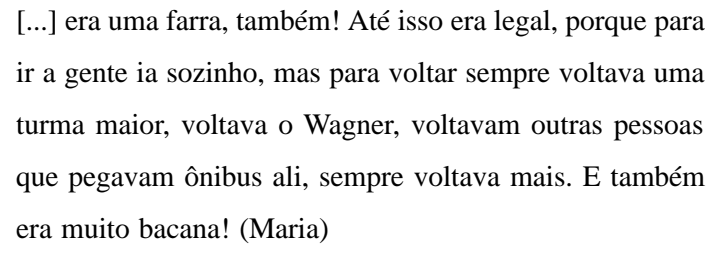

Embora não pareça ser uma prática comum entre os empregadores, a empresa em que Solange trabalhava facilitou-lhe a retomada dos estudos subsi-

${ }^{19}$ Essa combinação de local de trabalho com o de estudo parece ter sido fundamental em ambos os casos. Antes de ingressar no PROEF II, João chegou a dispensar a indicação de uma escola da rede privada que, na época, oferecia a trabalhadores a possibilidade de estudarem à noite, gratuitamente, por não poder assumir as despesas de transporte que o estudo em tal escola geraria. 
diando o transporte para a escola e reduzindo sua jornada diária em 30 minutos, para que ela pudesse chegar à universidade em tempo para o início das aulas. Entretanto, as facilidades referentes ao transporte e ao horário duraram pouco tempo: ela acabou saindo dessa empresa e voltando para o trabalho como diarista, para ganhar um pouco melhor, perdendo assim os benefícios que o emprego lhe garantia. A partir desse momento, Solange teve que arcar com o custo do transporte que variava em função da região na qual ela estivesse trabalhando e, ainda, lançar mão de estratégias que lhe possibilitassem reduzir despesas:

Eu morava no Alto do Vera Cruz. Para evitar de pegar muito ônibus eu pegava o [ônibus] São Francisco/São Geraldo aqui atrás, descia na Abadia e ia a pé até a minha casa. Às vezes, quando os professores davam carona para a gente até no Centro, para mim era mais fácil. Daqui lá em casa, com o trânsito bom era uma hora e meia praticamente. Eu saía às $10 \mathrm{~h} 10$. Chegava em casa mais ou menos às $11 \mathrm{~h} 30$, porque eu andava, andava bastante para tomar um ônibus só. ${ }^{20}$ (Solange)

Como se pode perceber com base em sua narrativa, a contrapartida dessa estratégia, no entanto, era alta: ela tinha que percorrer uma longa distância a pé, à noite, sozinha, após ter enfrentado uma jornada de trabalho pesado e uma segunda jornada de estudos em sala de aula, sem falar na terceira jornada que ainda a aguardava, em casa.

Nos quatro casos, o problema da alimentação pôde ser resolvido através de outros facilitadores: o sopão, que era servido no próprio PROEF II para os alunos, antes do início das aulas. Além do sopão, os alunos tinham o direito de jantar no bandejão da universidade. Através desses recursos eles tinham a possibilidade de satisfazer a necessidade de uma refeição intermediária entre a saída do trabalho e a chegada em casa (num período que poderia chegar a seis horas),

${ }^{20}$ Os horários são, respectivamente, 22 h10 e 23 h30. sem ter nenhuma despesa - no caso do sopão -, ou através do pagamento de um valor bastante acessível, cujo custo era inferior ao de um lanche simples no caso do bandejão. ${ }^{21}$

As reações negativas de algumas pessoas em relação à retomada dos estudos também foi uma barreira que se ergueu para os sujeitos que ingressaram no PROEF II. Nesse sentido, merecem destaque as reações esboçadas por familiares, cuja referência, nas quatro entrevistas, deu margem para que se percebesse, entre outras coisas, a maneira como o retorno aos estudos, no caso de pessoas adultas, é encarada so-

${ }^{21}$ Em conversa com uma pessoa ligada ao supletivo desde a sua criação, averiguou-se que a idéia de fornecer, no próprio PROEF II, uma sopa aos alunos antes do início das aulas partiu de um aluno, que sugeriu que a possibilidade fosse discutida no Restaurante Setorial, responsável pelo jantar oferecido à comunidade acadêmica. A então coordenadora do supletivo, professora Leonor Ferraz, conseguiu que o restaurante disponibilizasse uma panela de sopa cujo transporte ficava sob a responsabilidade da coordenadora. Assim, todas as noites a sopa era levada e servida aos alunos antes do início das aulas. Nessa época, também se conseguiu com a Fundação Mendes Pimentel (FUMP) um subsídio equivalente ao valor das refeições. Portanto, os que preferissem e tivessem tempo para tanto poderiam fazer uma refeição completa (almoço ou jantar) no próprio restaurante do campus da universidade ou em outros ligados à instituição. Não ficou esclarecida a causa do fim do sopão, nem da diminuição do subsídio no valor das refeições. De qualquer maneira, é importante ressaltar que o fato de os alunos terem acesso ao restaurante e também ao Clube Universitário (CEU), possuindo a carteirinha de estudante, aumentava a identificação deles, não só como alunos do PROEF II, mas como membros da comunidade universitária.

Ainda em relação ao sopão, é importante ressaltar que, além de ser uma estratégia pela qual se garantia aos alunos a alimentação, liberando-os de possíveis gastos, também assumia, conforme se percebeu pelas conversas sobre o assunto, o caráter de um momento de socialização, uma vez que eles podiam jantar juntos, em um mesmo local e horário, contando, inclusive, com a presença de monitores-professores e coordenadores que também os acompanhavam nessas refeições. 
cialmente. Solange, por exemplo, resolveu encarar a reação negativa do marido, não desistindo de aproveitar a oportunidade que se lhe apresentara:

Foi uma barra muito grande, na época meu marido falou que... Quando eu comecei a estudar aqui, meu marido falou que ia me largar. Aí eu falei: "Pois pode largar!". Porque eu quero uma coisa para mim, sabe? Eu sempre lutei para as coisas melhor para mim. Eu falei: "Então pode ir!". Falei mesmo com ele: "Você pode ir porque você é um homem, você é uma pessoa que não tem ambição". Porque ele acha que eu sou ambiciosa assim, do fato de eu querer ter um estudo, de ter uma posição melhor na vida, assim, de conseguir um emprego melhor... Então, ele acha que eu sou ambiciosa. Então eu falei com ele: "Não, você pode ir!". Eu bati o pé, falei que ia estudar, tal e tal, comecei a estudar, enfrentando brigas dentro de casa, não deixando isso atrapalhar o meu serviço, a minha escola, sempre tive notas boas. Mas quando ele viu mesmo que eu não arredei meu pé... ele tá lá até hoje! (Solange)

Como se não bastasse a necessidade de enfrentar o marido, chegando a pôr em cheque seu casamento, ela também teve que enfrentar a reação negativa de outros familiares, para os quais não fazia sentido sua busca por uma melhor formação escolar, uma vez que seu tempo para estudar já havia passado:

[...] quando eu comecei a estudar aqui, no CP, aí eu passei, assim, uma dificuldade muito grande, porque minhas irmãs falavam que eu já tinha muito diploma dentro de casa, que eram os filhos. Para que que eu ia caçar mais, não é? (Solange)

Segundo explicitado em sua narrativa, diante dessas provocações, ela se posicionava com a mesma firmeza que demonstrara diante do marido:

Eu sempre achei que a educação, o saber, nunca ocupa lugar. Eu tenho essa perspectiva comigo. Quanto mais você aprende, melhor é, isso ninguém tira de você. O conhecimento que você venha a ter, isso é uma coisa que a gente tem com a gente. Eu sempre lutei para isso! (Solange)
Tal como Solange, José também enfrentou, dentro de sua casa, reações negativas diante de sua decisão de retomar os estudos. Segundo ele, sua esposa:

Não viu com bons olhos, não, que ela é muito ciumenta, entendeu, ela estava achando que eu estava querendo era aprontar alguma coisa. No início ela não gostou muito, não. Ficou de cara feia... Tipo assim, fazia uma cara feia, jogava uns pontinhos, entendeu, umas indiretas, mas nunca passou disso! (José)

Questionado acerca das possíveis razões para a reação inicial da esposa e para a permanência da atitude negativa no decorrer do tempo, ele esclareceu que

\begin{abstract}
[...] era muito trabalho que tinha, não é? Porque, geralmen-
te, trabalhava durante o dia, estudava ali mesmo, no CP, e, geralmente, no final de semana, um feriado prolongado é que era o problema, porque tinha muita pesquisa para fazer, muito trabalho, e eu fui gostando do negócio, fui envolvendo, à medida em que foi passando, eu fui interessando, porque eu vi como que era bom, e aí começou os meus feriados, sábado, domingo, eu ficar todo envolvido lá com pesquisa, envolvido com os meninos e pergunta um, pergunta o outro, entendeu? (José)
\end{abstract}

Também os filhos, por razões diferentes daquelas que motivaram a reação negativa da esposa, colocaram-se, se não contrários, no mínimo em posição de estranhamento diante da decisão do pai:

[...] eles, assim... no início... tipo assim, eles não ficaram entusiasmados não, mas eu acho que até por eles estarem na adolescência, eles acharam assim aquele negócio estranho: "Pôxa, meu pai depois de velho voltar a estudar!". Entendeu? Eles não deram muito valor. É, se assustaram, no início, se assustaram um pouco: "Mas qual é a do meu pai?". Acho que eles pegaram mais como se eu estivesse assim tentando mostrar para eles que eles estudavam mas não davam tanto valor ao estudo igual eu dava valor, entendeu? (José)

Se assumir como aluno, após um longo período de afastamento dos bancos escolares, foi outro gran- 
de dificultador identificado nas quatro narrativas. A necessidade imperativa de desenvolver a disciplina necessária aos estudos, o pouco tempo livre para estudar em casa, o cansaço sentido após um dia inteiro de trabalho, a percepção de possuírem um ritmo diferente de aprendizagem, demandando mais tempo e atenção, tudo isso contribuiu para tornar ainda mais tensa e difícil a retomada da trajetória de escolarização. Nesse sentido, o relato de José sobre a necessidade de descansar ao término do curso é bem esclarecedor:

Nos seis primeiros meses tudo bem, era aquele negócio de descansar e tal, tal. Mas depois eu fui ficando assim tipo com saudade mesmo do pessoal, da turma. [...] É assim, o cansaço... Aquele negócio que você fala assim: "Ah, não, vou descansar um pouco, quero saber de dormir... chegar mais cedo em casa...”. [O ritmo da vida] tinha mudado muito, entendeu? Falei: “Ah, não, agora eu quero é chegar em casa mais cedo e não quero saber de fazer pesquisa sábado e domingo...”. Entendeu? Então, é por aí. Queria tentar voltar um pouco o ritmo anterior... Porque estudar era bom mas era algo que exigia muito, entendeu?! (José)

No caso de Solange, como já foi dito, o cansaço se fez sentir ao longo de todo o período durante o qual esteve estudando, dada a necessidade de enfrentar no mínimo três jornadas diárias, a saber: o trabalho, o cuidado da casa (incluindo aí filhos e marido) e ainda os estudos. Para dar conta de tudo isso, só mesmo diminuindo a noite para aumentar o dia, conforme demonstra essa passagem de sua narrativa:

[Eu] chegava, fazia comida... lavava roupa... passava a roupa, tomava um banho [...]. Começava a estudar. Algumas vezes eu já amanheci debruçada na mesa em cima dos cadernos. Saía às 7 horas. [...] Eu nunca fui de dormir muito não! [...] Acho que não chegava nem a quatro horas por noite. (Solange)

Outro elemento dificultador cuja superação fezse necessária por parte dos quatro egressos pesquisados foi a redução do (já limitado) tempo livre para passar em família, em virtude tanto da freqüência no curso quanto das atividades que tinham a fazer nos finais de semana:

Bom, eu tinha um tempo menor em casa, porque eu só ficava praticamente final de semana. [...] Eu chegava em casa à noite, fazia janta, arrumava a casa, tomava banho lavava o banheiro, já deixava tudo preparado para no outro dia de manhã sair com a Emanuelle. Eu deixava ela na casa da dona que tomava conta dela, pegava a Marcele, deixava na creche lá na Pompéia e ia para o serviço. [...] À tarde, quando ele [marido] não trabalhava, ele pegava a Marcele para mim no jardim e levava a Emanuelle. Ele dava banho, ele ajudava assim com as crianças, assim, dava banho, levava para passear... Portanto, a Emanuelle é mais apegada a ele nesse fato, pois ela ficou mais próxima dele do que eu. ${ }^{22}$ (Solange)

Ou seja, além de todo o cansaço da tripla jornada, Solange ainda se deparou com um distanciamento circunstancial dos filhos, ficando impedida, durante o período em que estudou, de acompanhar de perto a criação e o cuidado dos mesmos. Com relação a esse ponto, é importante ressaltar que se trata, no nosso entendimento, de um forte traço de gênero, característica da situação vivenciada por mulheres das camadas populares que, tendo família constituída, tentam dar prosseguimento à escolarização interrompida anteriormente..$^{23}$

De acordo com as falas dos sujeitos da pesquisa, depreendeu-se que, para superar as dificuldades com as quais foram se deparando, eles tiveram fortes aliados: os monitores-professores. Aparecendo nas narrativas e nos depoimentos como figuras sempre

${ }^{22}$ Emanuelle é a filha que tinha apenas cinco meses de idade quando Solange ingressou no PROEF II.

${ }^{23}$ É possível, inclusive, que essa realidade venha a somar-se aos demais obstáculos existentes, acabando por fazer com que muitas dessas mulheres desistam de suas tentativas, ou nem mesmo tentem elevar sua escolaridade. Contudo, trata-se de uma hipótese cuja confirmação requer mais estudos. 
atentas, carinhosas e dispostas a fazer a mediação entre o aluno e o conhecimento, respeitando seu ritmo e contribuindo para a superação de seus limites, afora as raras críticas a eles dirigidas, os monitoresprofessores podem ser considerados, seguramente, como um dos grandes motivadores/facilitadores da passagem dos sujeitos da pesquisa pelo PROEF II.

Apesar de serem alunos da universidade que estavam, na prática, formando-se como educadores de jovens e adultos, os monitores-professores (conforme eram chamados) desempenharam, inegavelmente, um papel fundamental na escolarização dos sujeitos da pesquisa, havendo também muitas referências a eles nos questionários que foram respondidos pelos egressos contactados ao longo da pesquisa. Quer fosse na disponibilização de uma carona que facilitasse a vida, na escuta atenta, na adoção de uma postura pedagógica de respeito ou, ainda, na presença em todos os momentos, incluindo aí os de lazer, os monitores apareceram nas narrativas como coadjuvantes cujo papel foi fundamental na caminhada dos sujeitos, contribuindo para a superação de parte dos obstáculos com que se depararam.

Essa constatação vai ao encontro da conclusão a que chegaram Llosa et al. (2001), acerca da maneira como jovens e adultos que vivenciaram experiências de escolarização tardia na Argentina se referem aos docentes. Segundo as autoras, na fala desses sujeitos

Se destaca la importancia que la relación con el docente tiene para estos adultos que acceden a la "segunda chance educativa”; relación que sobrepasa el vínculo del conocimiento. Se señala una imagen positiva del docente no sólo centrada en los procesos de enseñanza y aprendizage sino en los aspectos afectivos. Los jóvenes y adultos hablan de un docente "escucha", de un docente "continente" de sus problemáticas cotidianas y "consejero" para enfrentarlas. Aparece también el rol del docente a respecto de la demanda, como facilitador del ingreso y estimulador de la continuidad de los adultos en las instancias educativas. (2001, p. 32)

Para além das questões destacadas acima, a realização da pesquisa possibilitou constatar que, de for- ma geral, no caso dos sujeitos considerados, apesar de todas as dificuldades, os custos e os obstáculos (e provavelmente também pela existência destes), a vivência de uma experiência de escolarização tardia gerou impactos bastante positivos. Diante de tal constatação, conclui-se que a EJA promoveu a potenciação dos sujeitos pesquisados, uma vez que logrou utilizar o conhecimento e a experiência, mais depurados e ricos, da comunidade humana, para possibilitar-lhes o desenvolvimento consciente e autônomo de formas próprias de pensar, sentir e atuar (Gómez, 1997).

Outro impacto que a vivência de escolarização tardia parece ter gerado na vida dos sujeitos pesquisados, que não poderia deixar de receber destaque, é o fato de a experiência escolar, nesse caso, ter propiciado uma ampliação dos horizontes e perspectivas pessoais. Essa ampliação se mostrou geradora de projetos futuros que comprovam (independente de serem imediatos ou mais ambiciosos) o desejo e a possibilidade de imaginar uma mudança em relação ao presente vivido (Duschatzky, 1999). Considerando que a realidade que circunda os meios populares dificulta a visualização do futuro e a formulação de projetos pessoais e coletivos (Dayrell, 1989; Schmelkes, 1996) e que a baixa escolaridade tende a agravar ainda mais essa dificuldade, percebe-se que o fato de a experiência de escolarização tardia contribuir para que os sujeitos superassem essa dificuldade representa uma importante conclusão da pesquisa, sendo, por isso mesmo, merecedora de investigações que possibilitem sua melhor compreensão.

\section{Considerações finais}

Ao longo do trabalho de pesquisa, questionou-se a possibilidade de a EJA servir como instrumento pelo qual se possa fazer frente à exclusão social, minimizando alguns de seus efeitos. Questionou-se, igualmente, acerca da possibilidade de identificar nessa modalidade de ensino uma arma para a luta em favor da efetivação da cidadania. Muito embora se tenha consciência de que a extensão da pesquisa não permitiria obter resultados passíveis de generalização, é 
importante ressaltar que, no caso dos sujeitos pesquisados, a análise da vivência da experiência de escolarização tardia evidenciou que a EJA mostrou-se capaz de desempenhar esses papéis.

Entretanto, é necessário ressaltar que os impactos positivos da experiência de escolarização tardia, identificados na análise das narrativas dos quatro sujeitos pesquisados, não constituem, apenas, o resultado da ação desenvolvida no programa de EJA pelo qual passaram. Isso porque, conforme anunciado por Dubet e Martuccelli (1996), o que a escola fabrica é resultado da interação entre o que a instituição se propõe a realizar e o trabalho que o aluno, na qualidade de ator, realiza, construindo sua experiência.

Possivelmente, os resultados obtidos têm relação com o fato de a experiência em questão ter sido vivenciada na oportunidade educacional escolhida como campo de pesquisa - PROEF II -, que possui uma proposta pedagógica e metodológica que lhe conferem um formato bastante específico, funcionando em condições peculiares.

Diferentemente de refutar os resultados da pesquisa, o reconhecimento dessa especificidade deve ser encarado como a apresentação do desafio de que se desenvolvam pesquisas voltadas para a compreensão dessa oportunidade educacional. Através da realização de tais pesquisas será possível identificar os elementos de seu fazer educativo que, na interação com o trabalho desenvolvido pelos atores para os e com base nos quais esse fazer se desenvolve, redundam nos resultados anteriormente apresentados. Essa compreensão, por sua vez, possibilitará que tais elementos possam ser adotados em outras propostas educacionais voltadas para o atendimento de jovens e adultos pouco escolarizados ou não-escolarizados. Certamente a generalização desses elementos contribuirá de forma significativa para que os demandatários da EJA tenham acesso a oportunidades educacionais compatíveis com suas especificidades e necessidades formativas.

GEOVÂNIA LÚCIA DOS SANTOS, mestre em educação pela UFMG , é vinculada à Faculdade de Educação da Universidade
Estadual de Minas Gerais, na qual é professora designada e tutora do Projeto Veredas. Atua também como professora na Faculdade da Cidade de Santa Luzia e na Faculdade Metropolitana de Belo Horizonte. Trabalhos apresentados recentemente: O papel da escola no processo de elaboração de projetos futuros de jovens e adultos das camadas populares (I Semana de Pós-Graduação da Universidade Federal de Minas Gerais. Belo Horizonte: 13 a 18 de setembro de 1999); Pesquisando alunos egressos: a questão da preservação da memória nas instituições educacionais e sua importância para a realização de pesquisas desta natureza (VI Encontro de Pesquisa da FAE/UFMG. Belo Horizonte: 8 a 10 de novembro de 1999); Educação ainda que tardia: os impactos da exclusão da escola e da reinserção em um programa de EJA entre adultos das camadas populares $\left(13^{\circ}\right.$ Congresso de Leitura do Brasil COLE. Campinas: 17 a 20 de julho de 2001). No prelo: Quando adultos voltam para a escola: o delicado equilíbrio para obter êxito na tentativa de elevação da escolaridade (capítulo de uma coletânea sobre Educação de Jovens e Adultos, organizada por Leôncio José Gomes Soares, a ser publicada pela Editora Autêntica).E-mail : geolusantos@bol.com.br

\section{Referências bibliográficas}

ALMEIDA, M.L.S. de, (2002). Os significados atribuídos ao processo de alfabetização na voz do aluno adulto. Dissertação de mestrado. Faculdade de Educação da Universidade Federal de Minas Gerais.

ARAÚJO, D.A. de, (2001). O ensino médio na educação de jovens e adultos: um material didático de matemática e o atendimento às necessidades básicas de aprendizagem. Dissertação de mestrado. Faculdade de Educação da Universidade Federal de Minas Gerais.

CHAUI, Marilena, (1986). Conformismo e resistência ; aspectos da cultura popular no Brasil. $3^{\mathrm{a}}$ ed. São Paulo: Brasiliense.

DAYRELL, J. T., (1989). De olho na escola: as experiências educativas na ótica do aluno-trabalhador. Dissertação de mestrado. Faculdade de Educação da Universidade Federal de Minas Gerais.

DUBET, F., MARTUCCELLI, D., (1996). En la escuela: sociología de la esperiencia escolar. Buenos Aires: Losada.

DUSCHATZKY, S., (1999). La escuela como frontera: reflexiones sobre la experiencia escolar de jóvenes de sectores populares. Buenos Aires: Paidós. 
FONSECA, M. da C.F.R., (2001). Discurso, memória e inclusão: reminiscências da matemática escolar de alunos adultos do ensino fundamental. Tese de doutorado. Faculdade de Educação da Universidade de Campinas.

GÓMEZ, Angel Ignacio Pérez, (1997). Socialización y educación en la época postmoderna: ensayos de pedagogia crítica. Madrid: Editorial Popular.

HADDAD, Sérgio, (1998). Educação de pessoas jovens e adultas e a nova LDB. In : BRZEZINSKY, Iria (org.). LDB Interpretada: diversos olhares que se entrecruzam. São Paulo: Cortez.

JORGE, G.M. dos S., (1999). A sala de aula na educação de jovens e adultos : processos interativos. Dissertação de mestrado. Faculdade de Educação da Universidade Federal de Minas Gerais.

LLOSA, S. et al., (2001). La situación de la educación de jóvenes y adultos en la Argentina. Revista Brasileira de Educação, $\mathrm{n}^{\circ} 18$, p. 22-34, set.-dez.

MICHELAT, G., (1980). Sobre a utilização da entrevista nãodiretiva em sociologia. In: THIOLLENT, Michel J. M. Crítica metodológica, investigação social e enquete operária. São Paulo: Polis, p. 19-212.

PARENTI, Gabriela Maria Faiçal, (1999). Trabalhadores da construção civil e a experiência escolar : significados construídos em um curso de aperfeiçoamento profissional. Dissertação de mestrado. Faculdade de Educação da Universidade Federal de Minas Gerais.
PROGRAMA de Educação Básica de Jovens e Adultos, (1998). Da alfabetização ao ensino médio. Belo Horizonte: FaE/UFMG, (mimeo.).

, (1996). Projeto de ensino fundamental (equivalente ao ciclo de $5^{a}$ à $8^{a}$ série) e formação de jovens e adultos. Belo Horizonte: UFMG/PROEx/CP, FaE (mimeo.).

SCHMELKES, Sylvia, (1996). Las necesidades básicas de aprendizaje de los jóvenes y adultos en América Latina. In: OSORIO VARGAS, Jorge, RIVERO HERRA, José (comps.) Construyendo la modernidad educativa en América Latina: nuevos desarrollos curriculares en la educación de personas jóvenes y adultas. Lima: OREALC, UNESCO, CEAAL; Tarea, p. $13-43$.

SOUZA, M.P. et al., (1999). O resgate do desejo de aprender: uma experiência educacional bem-sucedida em uma classe de aceleração. Trabalho apresentado na $22^{\mathrm{a}}$ Reunião Anual da ANPEd, Caxambu, MG, set. CD-ROM.

ZAGO, N., (2000). Processos de escolarização nos meios populares. In : NOGUEIRA, Maria Alice, ROMANELLI, G., ZAGO, N. (orgs.). Família e escola: trajetórias de escolarização em camadas médias populares. Petrópolis: Vozes. p. 17-44.

Recebido em outubro de 2002 Aprovado em março de 2003 